\title{
Wind Energy System Load Analysis with Voltage Regulator Controller based STATCOM
}

\author{
Abhishek Kumar Anand* and Girraj Prasad Rathor \\ Department of Electrical \& Electronics Engineering, Technocrats Institute of Technology, Bhopal, India \\ *Corresponding author: abhishekanand.anand17@gmail.com
}

\begin{abstract}
The RMS values of the voltage outputs from the wind energy system where the speed of wind varies between 0 to $25 \mathrm{~m} / \mathrm{s}$ has been observed. It is made to drive the heavy loads and the drop in the voltage outputs is being observed and compared with the system having the STATCOM with AC DC voltage regulation controller. The load has been varied continuously to observe the optimum value of load up to which both the systems are compatible. The waveform of the open circuit voltage output has a variation up to 800 to 1000 volts. This voltage should be maintained when it is made to drive any load without dropping in its value. It was observed that the voltage dip in system without STATCOM is more while driving 1000 KW load. However, the Optimum value of the system upto which it can drive load is $18 \mathrm{KW}$ and with STATCOM having AC DC voltage regulation controller It has improved to $50 \mathrm{KW}$.
\end{abstract}

Keywords: Wind Energy, DFIG, Voltage Regulator, STATCOM, MATLAB

Electricity is the most common source of energy for families, workplaces and industry. Population and industrial growth have led to a significant increase in electricity consumption over the past three decades ${ }^{[1]}$. Natural resources such as coal, oil and gas, which have powered power plants, industries and vehicles for many decades, are running out very quickly. This serious problem has prompted nations around the world to consider alternative forms of energy that use inexhaustible natural resources ${ }^{[2]}$.

The burning of conventional fossil fuels worldwide has caused an increase in pollution. Numerous international conventions and forums have been established to address and solve the problem of climate change. These forums prompted countries to develop national energy policies that address pollution control, energy saving and energy efficiency and the development of alternative and clean energy sources ${ }^{[3]}$. 


\section{(A) DFIG Configuration}

The generator is configured using a wound rotor induction generator (WRIG) with the stator windings connected directly to the network and the rotor windings connected to the stator terminal via the AC / DC / AC converter. A transformer is used to regulate the voltage levels between the network and the converter on the network side. The layout of the DFIG configuration is illustrated in Fig. 1.

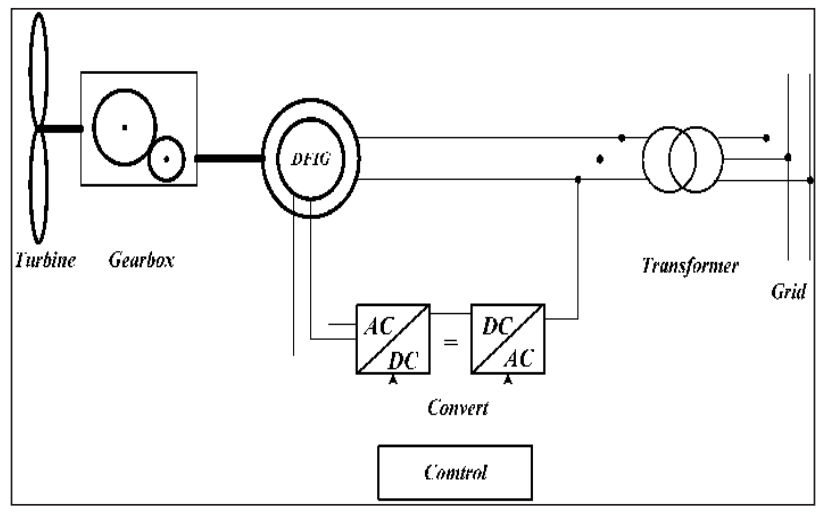

Fig. 1: DFIG Configuration ${ }^{[1]}$

The back-to-back converter is a bidirectional power converter consisting of two conventional voltage source converters with pulse width modulation (PWM) and a common DC bus with an intermediate circuit capacitor. Back-to-back converters are often used in DFIG-based systems for wind applications to generate more energy. Depending on the decoupled control strategy and complexity, DFIG can operate in both the sub-synchronous and super-synchronous speed range. This type of conversion system consists of two PWM converters with an intermediate circuit capacitor. The GSC must be checked so that the DC link voltage remains constant and is also responsible for controlling the reactive power of DFIG and the grid. The rotor side converter control strategy (RSC) essentially takes into account the control of the electromagnetic torque and the excitation currents of the rotor.

\section{LITERATURE REVIEW}

Zhao Xu et al. ${ }^{[2]}$ proposed an extended control strategy for the line side rotor and converters of the double power wind turbine (DF) based on an induction generator (DFIG) in order to improve the low voltage throughput capacity (LVRT) in accordance with requirements network connection. As part of the new control strategy, the rotor side control can convert the unbalanced power into the kinetic energy of the WT by increasing the speed of its rotor in the event of low voltage due to a mains error, e.g. the common coupling point (CCP). The proposed line side control scheme introduces a compensation term which reflects the instantaneous intermediate circuit current of the converter on the rotor side in order to attenuate the fluctuations of the intermediate circuit voltage during the line failure.

Ammar F. et al. ${ }^{[3]}$ proposed suitable designs of integrated proportional controllers (PI) for rotor side converters (RSC) and grid side converters (GSC) of the wind turbine type with double power induction generator (DFIG) to control current, voltage and power on the RSC side and the performance on the GSC side of the wind energy conversion system (WECS). Furthermore, the proposed controls have 
been designed to reduce the overshoot fault current when different types of disturbances have occurred. The optimal design of the parameters of the proposed PI controllers is also represented by intelligent techniques, namely: optimization of bee colonies (BCO). The first step in this document is to limit the PI controller based on the trial and error method to examine the full performance of the WECS system.

Guo, Y. et al. ${ }^{[4]}$ proposed an improved voltage control strategy (EVCS) based on the predictive control model (MPC) for high voltage direct current converted to voltage (VSCHVDC) connected to offshore wind farms (OWF). In the proposed MPC-based EVCS, all wind turbine generators (WTG) and the VSC on the wind farm side are optimally coordinated in order to maintain tensions within the achievable range and reduce system performance losses. Given the high ratio of the OWF sensor system, the effects of the active power produced by wind turbines on voltage regulation are also taken into consideration.

Sudhasmita Behera et al. ${ }^{[5]}$ shown renewable, reliable and clean energy, wind energy attracted more attention. In this article, the analysis and modeling of the variable speed DFIG (induction generator with dual power supply) were presented and the control strategy was examined in two operating modes. Depending on the wind speed, the DFIG-based wind turbine can operate in sub and super synchronous operating mode with a back to back PWM converter.

Bharti et al. ${ }^{[6]}$ analyzed the driving force and main causes of voltage instability. Different methods and devices used to enhance voltage stability are also explained. The steady-state and dynamic modelling of the power system devices including wind generators and photovoltaic units have been discussed.

\section{METHODOLOGY}

The model has been developed in MALAB/SIMULINK environment. This is a high-level matrix/array language with control flow statements, functions, data structures, input/output, and object-oriented programming features. It has following key features:

$\square$ High-level language for scientific and engineering computing

$\square$ Desktop environment tuned for iterative exploration, design, and problem-solving

$\square$ Graphics for visualizing data and tools for creating custom plots

$\square$ Apps for curve fitting, data classification, signal analysis, control system tuning, and many other tasks

$\square$ Add-on toolboxes for a wide range of engineering and scientific applications

$\square$ Tools for building applications with custom user interfaces

$\square$ Royalty-free deployment options for sharing MATLAB programs with end users

The modeling of Dual Voltage Source Inverter system is done which is capable of feeding the load with either solar or wind resources depending on the availability thus making the system more reliable

\section{(B) Wind Energy System Modelling}

Model of wind turbine with PMSG Wind turbines cannot fully capture wind energy. Output aerodynamic power of the wind-turbine is expressed as in equation (i): 


$$
P_{\text {Turbine }}=\frac{1}{2} \rho \mathrm{A} C_{p}(\lambda, \beta) v^{3}
$$

where, $\rho$ is the air density (typically $1.225 \mathrm{~kg} / \mathrm{m}^{3}$ ), $A$ is the area swept by the rotor blades (in $\mathrm{m}^{2}$ ), $C_{P}$ is the coefficient of power conversion and $v$ is the wind speed (in $\mathrm{m} / \mathrm{s}$ ). The tip-speed ratio is defined as in equation (ii):

$$
\lambda=\frac{\omega_{m} R}{v}
$$

Where $\omega_{m}$ and $R$ are the rotor angular velocity (in $\mathrm{rad} / \mathrm{sec}$ ) and rotor radium (in $\mathrm{m}$ ), respectively.

The wind turbine mechanical torque output $m T$ given as in equation (iii):

$$
T_{m}=\frac{1}{2} \rho \mathrm{A} C_{p}(\lambda, \beta) v^{3} \frac{1}{\omega_{m}}
$$

The power coefficient is a nonlinear function of the tip speed ratio $\lambda$ and the blade pitch angle $\beta$ (in degrees). Then Power output is given by,

$$
P_{\text {Turbine }}=\frac{1}{2} \rho \mathrm{A} C_{p_{\max }} v^{3}
$$

A generic equation is used to model the power coefficient $C_{P}$ based on the modeling turbine characteristics described in equation (v):

$$
C_{p}=\frac{1}{2}\left(\frac{116}{\lambda_{i}}-0.4 \beta\right) e^{-\left(\frac{21}{\lambda_{i}}\right)}
$$

For each wind speed, there exists a specific point in the wind generator power characteristic, MPPT, where the output power is maximized ${ }^{[5]-[7]}$. Thus, the control of the WECS load results in a variable-speed operation of the turbine rotor, so the maximum power is extracted continuously from the wind.

This mechanism uses the variable torque output $w_{m}$ and tries to optimize the output current and voltage waveform to its maximum value.

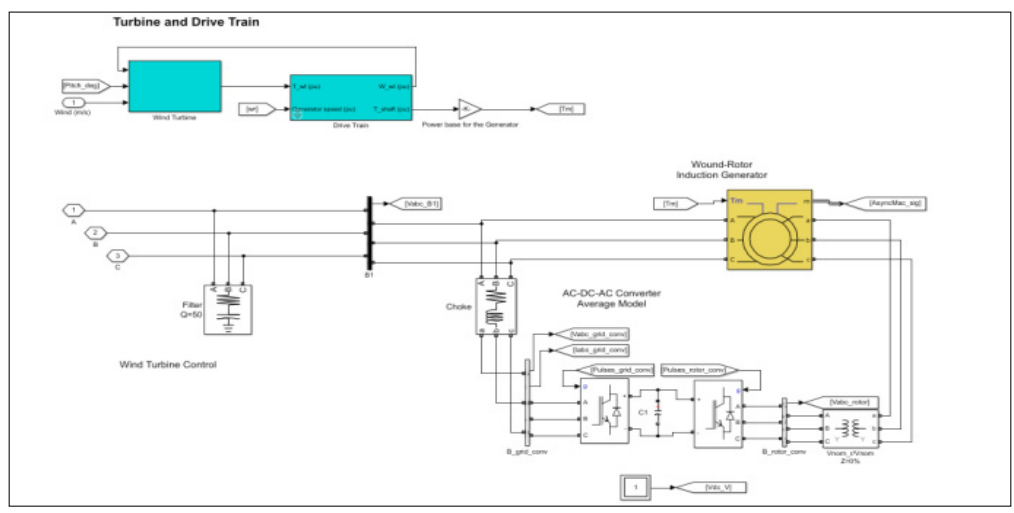

Fig. 2: MATLAB/SIMULINK Model of DFIG 


\section{Wind Energy System}

The generator side converter controls the generator speed for maximum energy consumption. The converter on the network controls the voltage on the intermediate circuit and the reactive power flow between the wind turbine and the network. Another control for the WT is the height control. It is applied to the rotor blades and modifies the angle of attack of the blades so that the output power can be controlled at high wind speeds ${ }^{[8]-[10]}$. The rotor of the turbine converts the floating wind energy into mechanical energy, which is converted into electrical energy via the generator, then transferred to the network via a transformer and transmission lines.

Wind turbines record wind force using aerodynamic blades and convert it into rotating mechanical force. The generator converts mechanical energy into electrical energy, which can be injected into a network via an electronic power converter and a transformer with automatic switches and electric meters.

\section{(C) Modelling of STATCOM}

In this document, a STATCOM is added to the power grid to provide dynamic voltage regulation for the wind farm. FACTS are an aspect of the power electronics revolution that has taken place in all areas of electricity. These controls offer better adaptation to different operating conditions and improve the use of existing systems. The FACTS controller is an electronic power supply system that allows you to control one or more parameters of the AC transmission system (serial impedance, shunt impedance, current, voltage, phase angle).

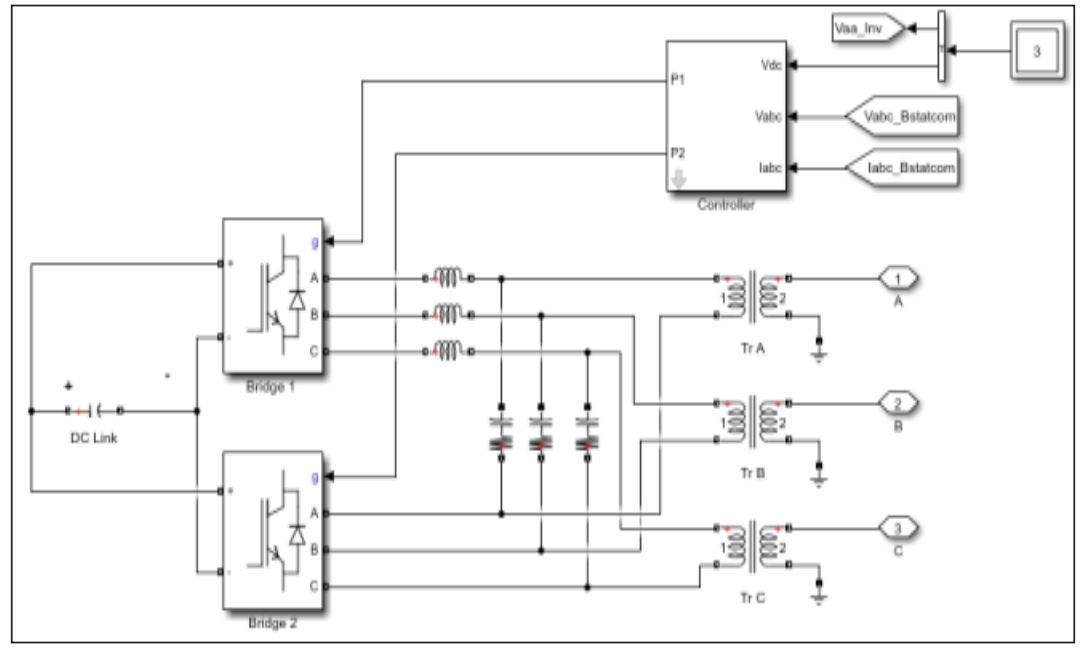

Fig. 3: MATLAB/SIMULINK model of the STATCOM used

STATCOM is a new generation of VSC-based reactive power compensators. It has a property similar to a synchronous capacitor, but since it is an electrical device, it has no inertia and is superior to the synchronous capacitor in several respects. STATCOM consists of a VSC with a capacitor on the DC side of the converter and a shunt transformer. The voltage source converter is generally built with interruption thermistors such as door closers (GTO) or today door switching thermistors (IGCT) or with IGBT-based converters (isolated gate bipolar transistors). The configuration of the STATCOM circuit is presented. 
As already mentioned, STATCOM can be treated as a synchronous voltage source because its output voltage can be controlled as desired. STATCOM works in bus voltage control mode. In this model, the D-STATCOM regulates the voltage of the B3 bus by absorbing or generating reactive power. The power is transmitted through the leakage reactance of the coupling transformer generating a secondary voltage in phase with the primary voltage.

As already mentioned, STATCOM can be treated as a synchronous voltage source because its output voltage can be controlled as desired.

\section{(D) AC DC Voltage Regulation Controller}

The voltage regulation of the controller operates by taking the output voltage of the transformer as a AC reference signal. The signal is first passed through second order filter to eliminate the harmonics and then dq form is obtained from abc form. The control will begin if, $V_{m}(t) \neq V s s$. The measured bus voltage $V_{m}(t)$ is compared with $V_{\text {ref }}(t)$.

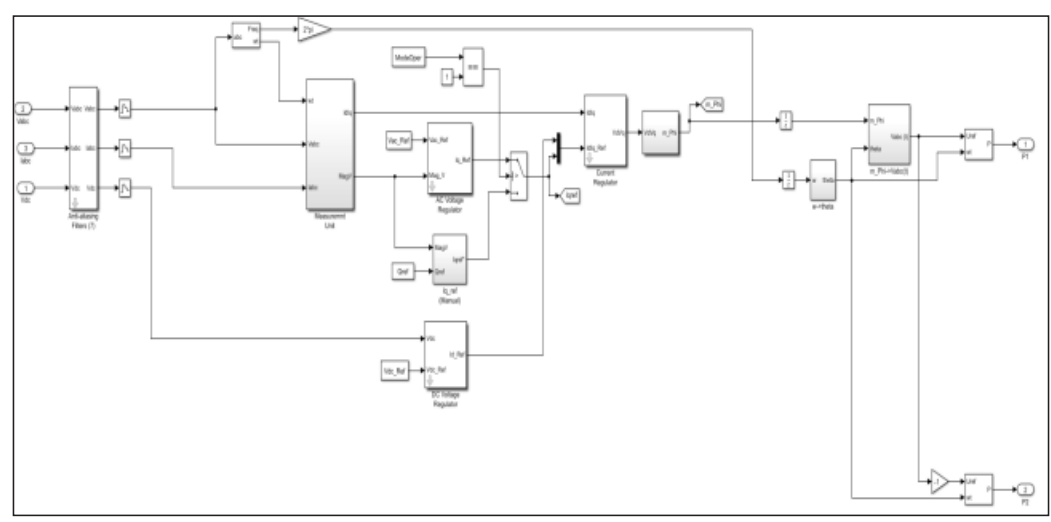

Fig. 4: MATLAB/SIMULINK Model AC DC Voltage Regulation Controller for STATCOM

Then, gain adjustments on $\mathrm{Kp} \_\mathrm{V}$ and $\mathrm{Ki} \mathrm{V}_{\mathrm{V}}$ are done in the outer loop i.e., voltage regulator block and thereby an updated Iqref is obtained through the current limiter as shown in Fig. 4. Then, this Iqref and measured q-current Iq are compared. The control gains $\mathrm{Ki} I(\mathrm{t})$ and $\mathrm{Kp} \_\mathrm{I}(\mathrm{t})$ can be adjusted. At last the phase angle $\alpha$ is determined and given through a limiter for output. Kit is then fed as pulses to the universal bridges for regulation.

Table 1: Control System Parameters

\begin{tabular}{cc}
\hline System Parameter & Values \\
\hline$A C$ voltage set point $\left(\mathrm{V}_{\mathrm{ref}}\right)(\mathrm{pu})$ & 1 \\
$\mathrm{~V}_{\mathrm{ac}}$ regulator gains $\mathrm{K}_{\mathrm{p},}$ & 0.55 \\
$\mathrm{~V}_{\mathrm{ac}}$ regulator gains $\mathrm{K}_{\mathrm{i}}$ & 2500 \\
$\mathrm{~V}_{\mathrm{dc}}$ regulator gains $\mathrm{K}_{\mathrm{p},}$ & 0.001, \\
$\mathrm{~V}_{\mathrm{dc}}$ regulator gains, $\mathrm{K}_{\mathrm{i}}$ & 0.15 \\
Current regulator gain $\mathrm{K}_{\mathrm{p},}$ & 0.8 \\
Current regulator gain $\mathrm{K}_{\mathrm{i} .}$ & 200 \\
\hline
\end{tabular}




\section{RESULTS AND DISCUSSION}

\section{(A) Simulation Environment}

MATLAB stands for MATrix Laboratory, which is a programming package exclusively designed for speedy and effortless logical calculations and Input/output. It has factually hundreds of inbuilt functions for a large form of computations and plenty of toolboxes designed for specific analysis disciplines, as well as statistics, optimization, solution of partial differential equations, information analysis.

In this research work MATLAB platform is used to show the implementation or simulation of implemented algorithm performance. Measurement toolboxes are used and some inbuilt functions for generating graphs are used. Simulation results and comparison of the performance of implemented model with some existing ones are calculated by MATLAB functions.

\section{(B) Model Description}

The first model was created by modeling of wind energy system integrated with the grid and feeding a balanced load and is compared by varying its condition. In the first model the system is made to drive the load without using AC DC voltage regulator controller based STATCOM via transformer. Further in this work the voltage profile of the wind energy system has been improved using a STATCOM based on AC DC voltage regulator controller. The voltage profile of the output from the system was again analyzed to observe the difference in the two models. Load analysis of the two system has been done by checking the amount of load it can handle independently and how AC DC voltage regulator controller proves to be beneficial in handling high loads. Also further the wind energy system model has been integrated with the grid in order to enhance the efficiency and reliability of the system.

\section{(C) Only Wind Energy System Driving 1000KW Load}

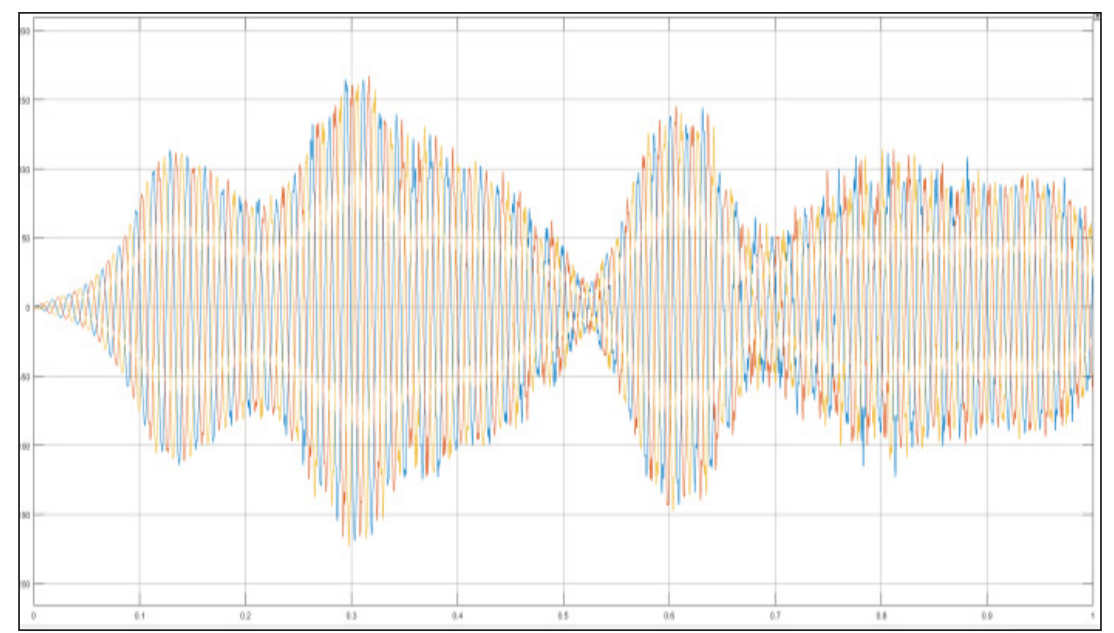

Fig. 6: Voltage Output from Wind Energy System only with 1000KW Load 


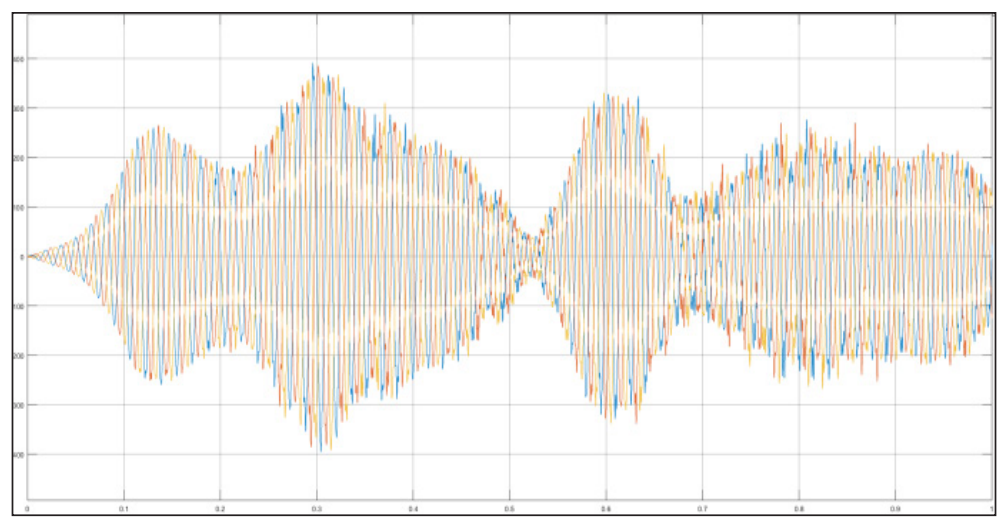

Fig. 7: Current Output from Wind Energy System only with 1000KW Load

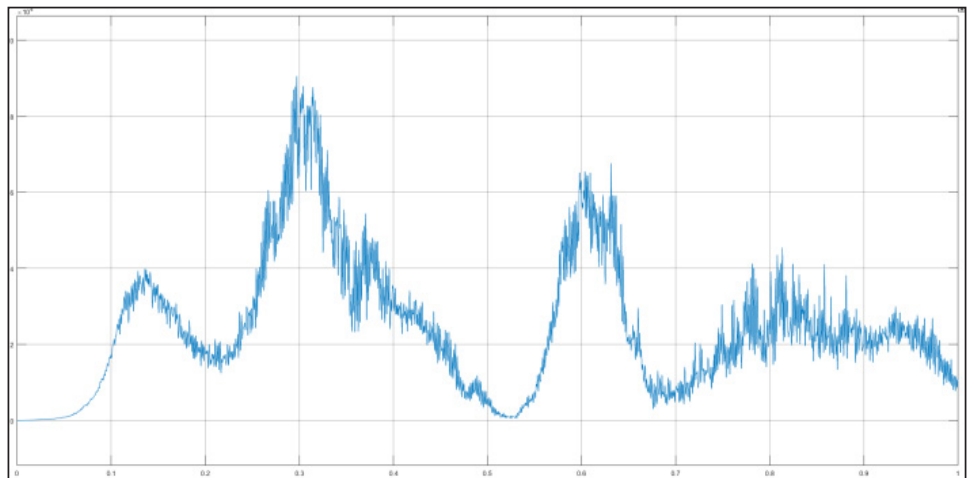

Fig. 8: Active Power Output from Wind Energy System only with 1000KW Load

(D) Wind Energy System Driving 1000KW Load with Voltage Controlled AC DC Regulator

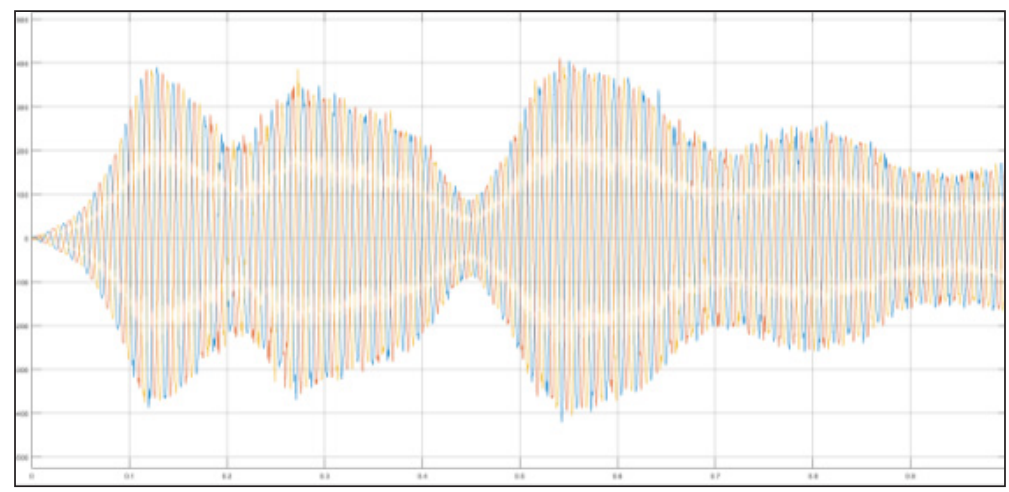

Fig. 9: Voltage Output from Wind Energy System with Voltage Controlled AC DC Regulator and 1000 KW Load 


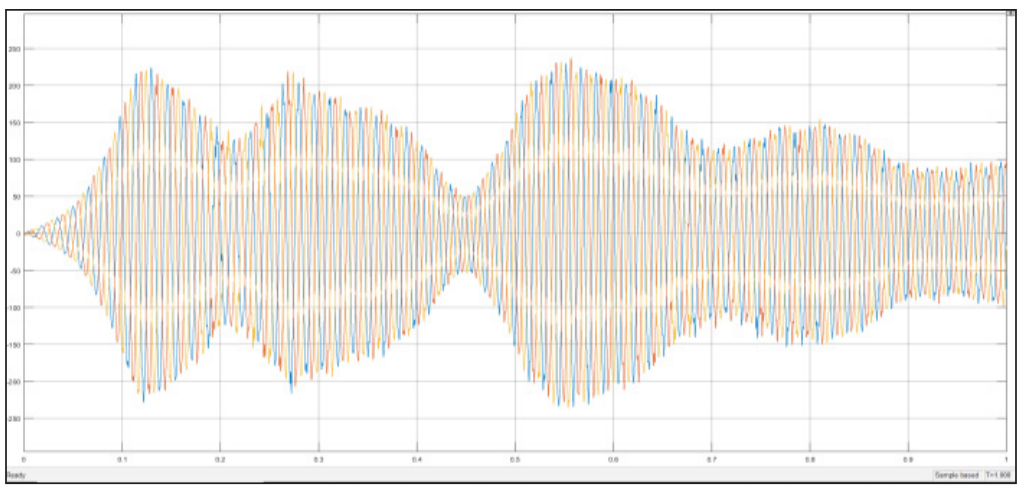

Fig. 10: Current Output from Wind Energy System with Voltage Controlled AC DC Regulator and 1000 KW Load

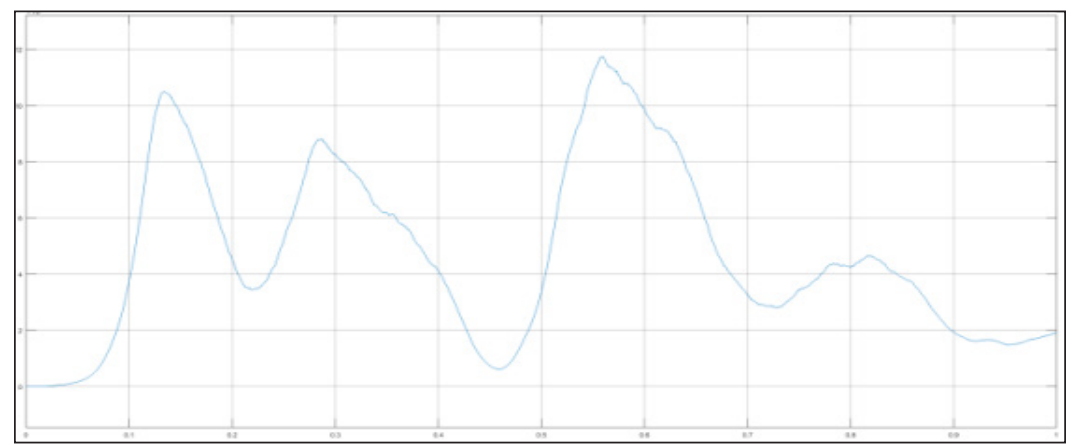

Fig. 11: Power Output from Wind Energy System with Voltage Controlled AC DC Regulator and 1000 KW Load

\section{(E) Outputs with optimum Load}

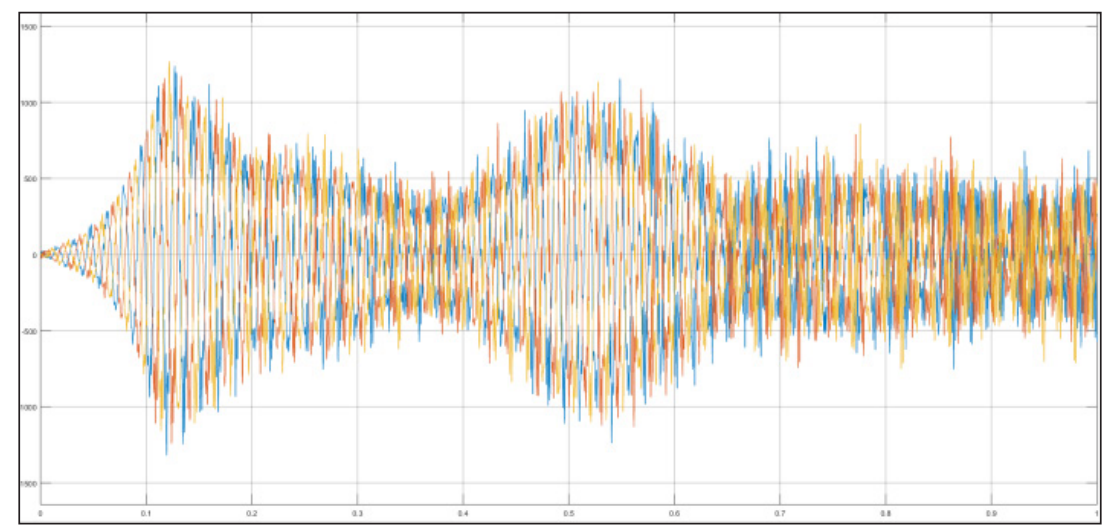

Fig. 12: Voltage with $18 \mathrm{KW}$ in System having No STATCOM 


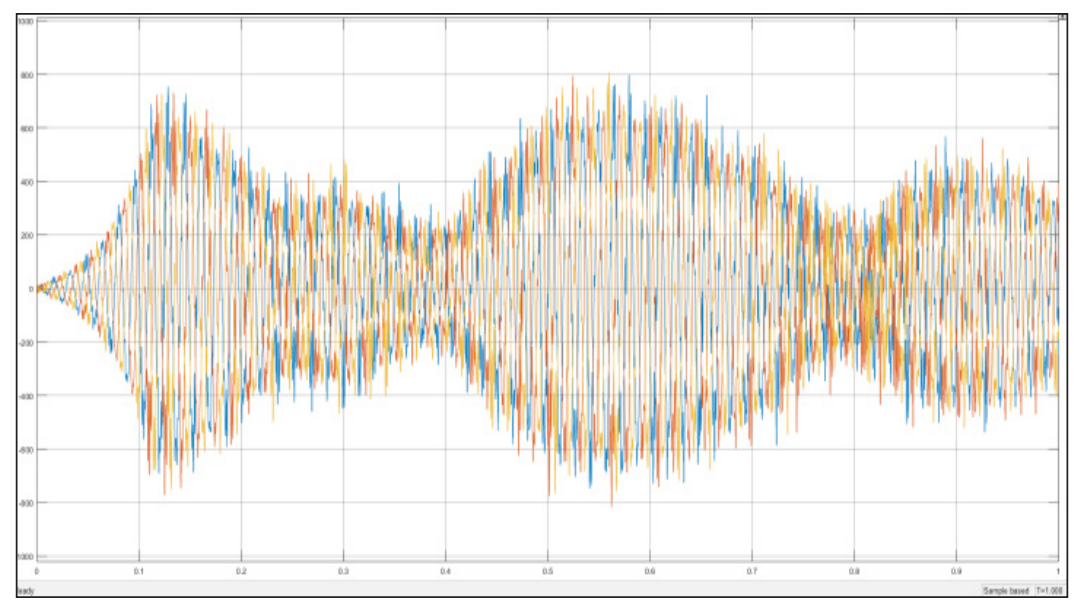

Fig. 13: Voltage with $50 \mathrm{KW}$ in System having STATCOM

From the above two waveforms of the two systems it is clearly observed that the voltage output of the system at the load terminal is maintained with their respective loads without experiencing any dip from the open circuit voltage waveform. The system with STATCOM having AC DC voltage regulation controller can drive the load of up to $50 \mathrm{KW}$ as compared to the system without the device which can drive a load of up to $18 \mathrm{KW}$.

\section{(F) Final Integration of the Systems with Grid}

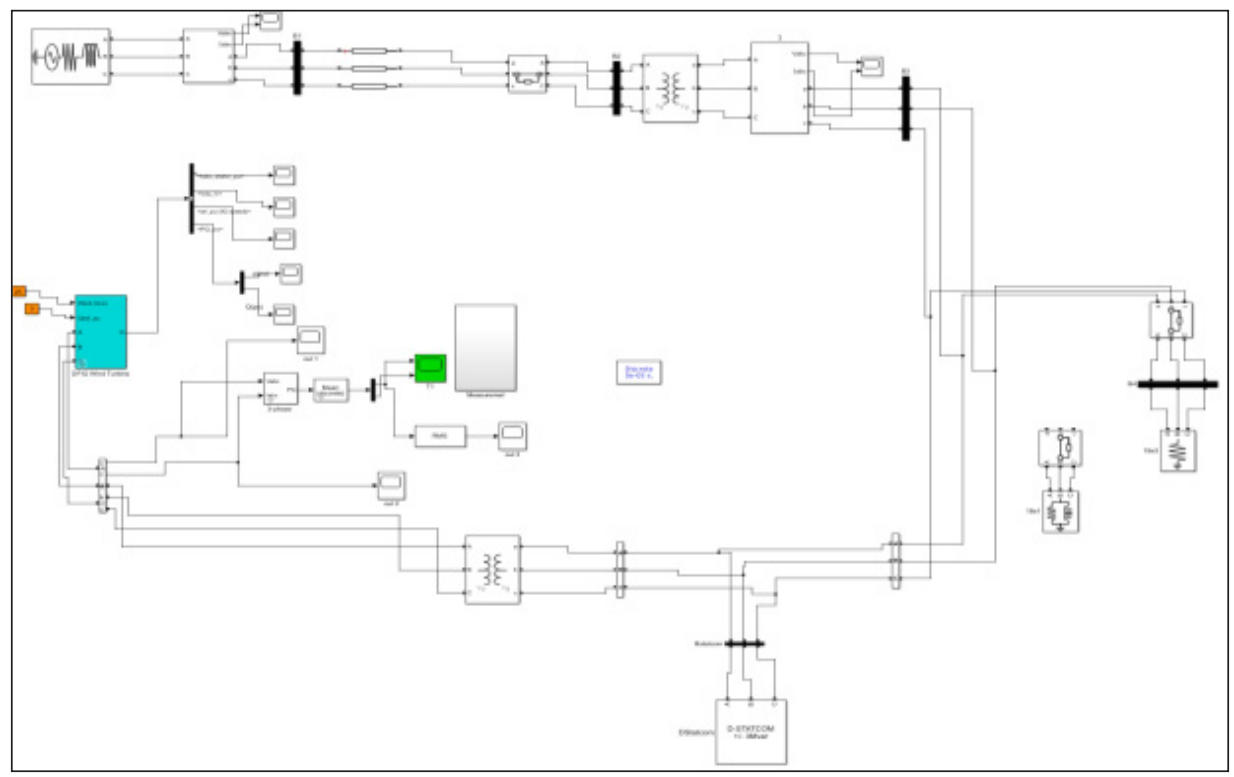

Fig. 14: System Integrated with Grid 


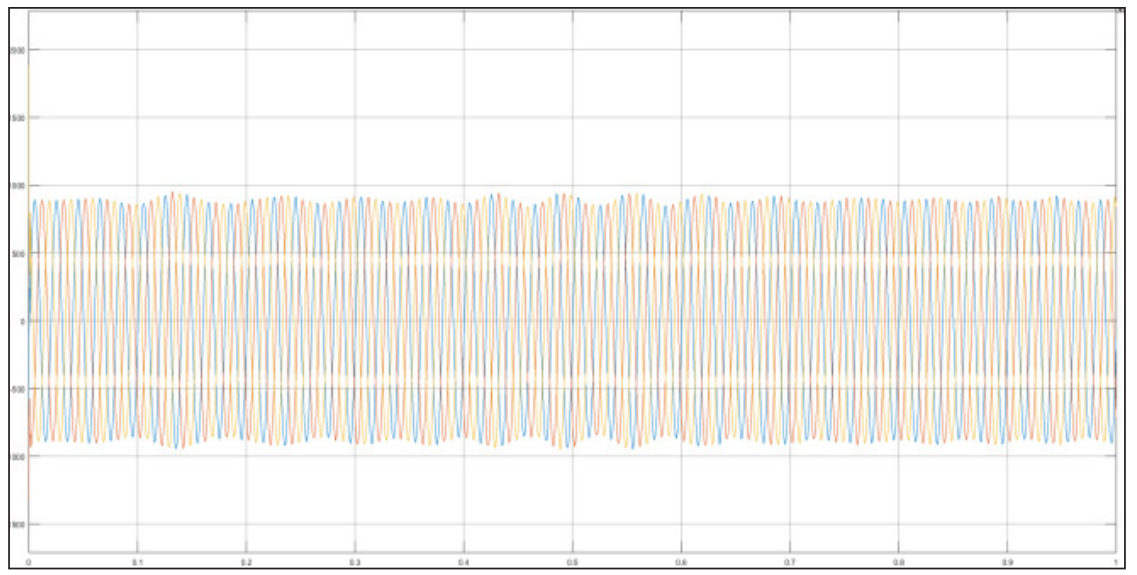

Fig. 15: Voltage Output with system connected with the grid

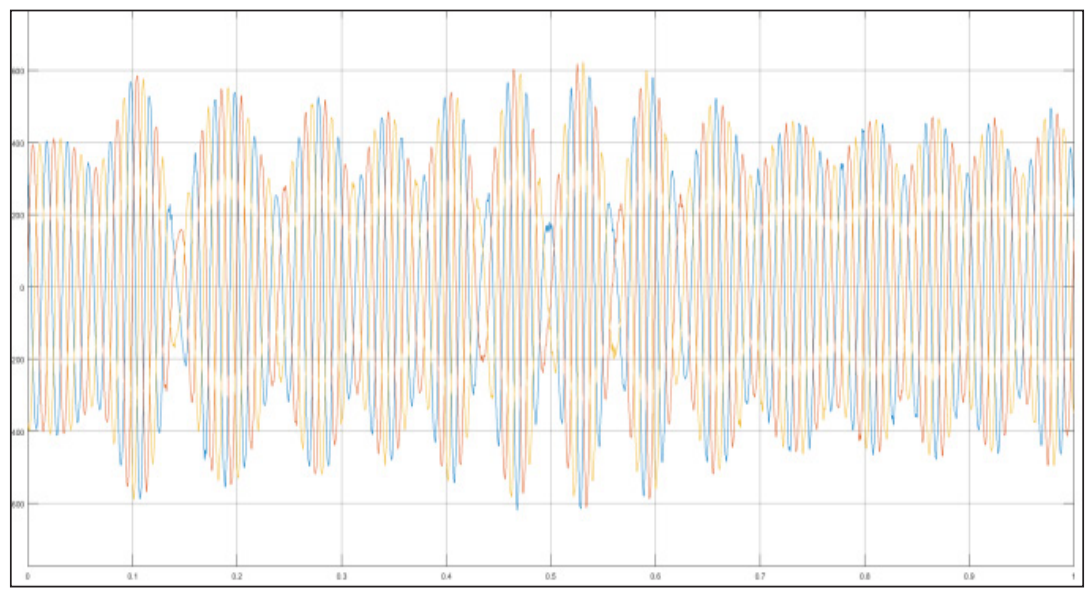

Fig. 16: Current Output with system connected with the grid

The output from the grid system has maintained the grid voltage of about 1100 volts. This voltage is the final grid voltage which is constant. When we change the load connected to it the power demand changes and hence the output current can vary according to changes in the load.

\section{(G) Validation}

In this work while validating the outputs following waveforms were observed. The RMS values of the voltage outputs from the wind energy system where the speed of wind varies between 0 to $25 \mathrm{~m} / \mathrm{s}$ has been observed. It is made to drive the heavy loads and the drop in the voltage outputs is being observed and compared with the system having the STATCOM with AC DC voltage regulation controller. The load has been varied continuously to observe the optimum value of load up to which both the systems are compatible. 


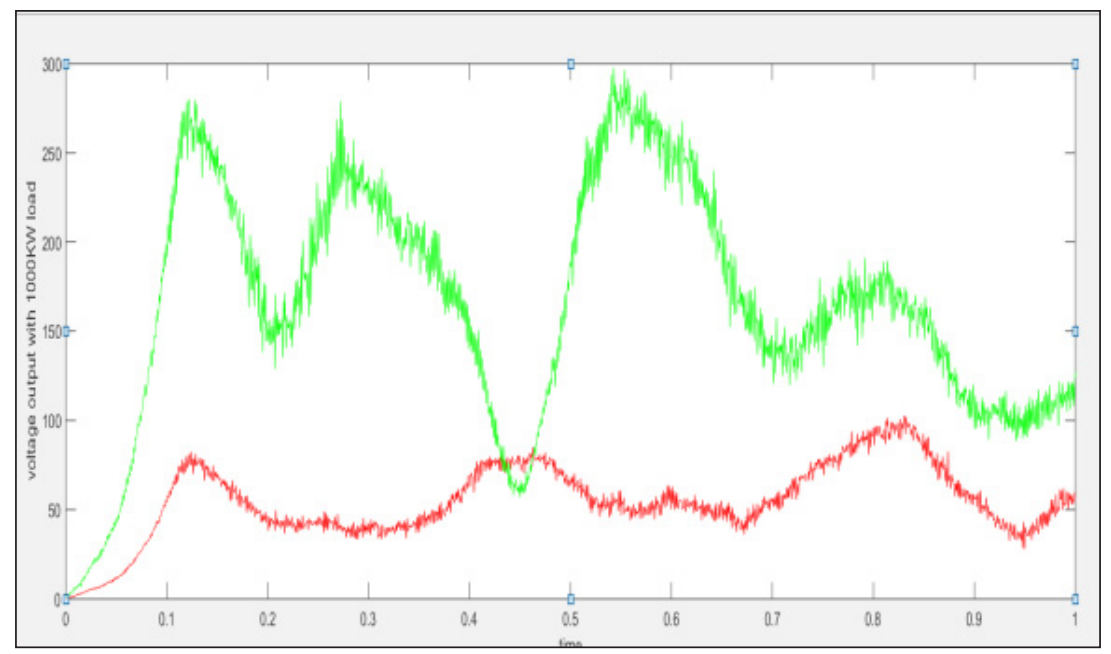

Fig. 17: Comparative values of Voltage Waveform from the System Driving 1000KW load

While driving heavy loads with $1000 \mathrm{KW}$ power requirement it was observed that the voltage dip in system without STATCOM is more where the voltage has been dropped in between 50 volts to 100 volts. The system with STATCOM has variation between 150 volts to 300 volts and hence is maintaining the voltage level to certain extent.

The system with STATCOM with AC DC voltage regulation has variation between 150 volts to 400 volts and hence is maintaining the voltage level to certain extent according to the wing speed variation. Hence it can be concluded that the voltage profile is improved with the STATCOM with AC DC voltage regulation. Later this system is integrated with the grid.

\section{CONCLUSION}

The work here discusses the main component of a grid connected wind energy conversion system includes wind turbine, gearbox, generator, power electronic interface and a transformer for grid connection.

The speed of wind varies between 0 to $25 \mathrm{~m} / \mathrm{s}$ and with this variation voltage outputs from the wind energy system has been observed. It is made to drive the heavy loads and the drop in the voltage outputs is being observed and compared with the system having the STATCOM with AC DC voltage regulation controller. The following conclusions were drawn:

Table 2: Comparative Table for Voltage Outputs with Different Loads

\begin{tabular}{cccccc}
\hline \multirow{2}{*}{ Variation in load } & \multicolumn{2}{c}{ Voltage level } & \multicolumn{2}{c}{$\begin{array}{c}\text { Drop from open circuit voltage (800 to 1000 } \\
\text { volts) }\end{array}$} \\
\cline { 2 - 5 } & Without STATCOM & With STATCOM & Without STATCOM & With STATCOM \\
\hline $1000 \mathrm{KW}$ & 50 to 100 volts & 150 to 300 volts & Approx. 700 volts & Approx. 500 volts \\
\hline
\end{tabular}

Hence, it can be concluded that the voltage profile is improved with the STATCOM with AC DC voltage regulation. Later this system is integrated with the grid. 
The system with STATCOM having AC DC voltage regulation controller can drive the load of up to $50 \mathrm{KW}$ as compared to the system without the device which can drive a load of up to $18 \mathrm{KW}$.

$\square$ It was found clearly that the voltage output of the system at the load terminal is maintained with their respective loads without experiencing any dip from the open circuit voltage waveform.

$\square$ System efficiency is enhanced after its integration with the grid. The voltage level is constant and current shows variation according to load demand.

\section{REFERENCES}

1. Yingning Qiu, Wenxiu Zhang, Mengnan Cao, Yanhui Feng and David Infield, 2015. “An Electro-Thermal Analysis of a Variable-Speed Doubly-Fed Induction Generator in a Wind Turbine”, Energies, 8(5): 33863402.

2. Lihui Yang, and Zhao Xu 2012. "Advanced Control Strategy of DFIG Wind Turbines for Power System Fault Ride Through" IEEE Transactions on Power Systems, 27(2).

3. Ammar F. Hameed 2017. "Performance Enhancement of a Wind Power System Based on Bee Colony Optimization Approach" inpressco, 7(6).

4. Guo, Y., Gao, H., Wu, Q., Zhao, H.J. and Shahidehpour, M. 2018. "Enhanced Voltage Control of VSCHVDC Connected Offshore Wind Farms Based on Model Predictive Control". IEEE Transactions on Sustainable Energy, 9(1).

5. Sudhasmita Behera, and Madhu Singh 2015. "modeling and control of dfig based wind generator under sub to super synchronous mode of operation" International Journal of Electrical, Electronics and Data Communication, 3(7).

6. Bharti V.A. and Gupta, R. 2018. "Study on Power Enhancement Technologies of Inverters in PV Wind Energy Systems”, Smart Moves Journal IJOSCIENCE, 4(2): 5.

7. Julius Mwaniki, and Hui Lin 2017. “A Concise Presentation of Doubly Fed Induction Generator Wind Energy Conversion Systems Challenges and Solutions” JE Volume 2017, Article ID 40151022017.

8. Marouane El Azzaoui, and Hassane Mahmoudi. 2017. "Modeling Control and Analysis of a Doubly Fed Induction Generator Based Wind Turbine System: Optimization of the Power Produced" wseas transactions on power systems E-ISSN: 2224-350X Volume 12, 2017.

9. Andrés Peña Asensio, and Santiago Arnaltes Gómez. 2018. "A Voltage and Frequency Control Strategy for Stand-Alone Full Converter Wind Energy Conversion Systems” EPECS26 January 2018; Accepted: 20 February 2018; Published: 25 February 2018.

10. Peiyuan Li and Jianwen Zhang. 2017. "DC bus current optimization control strategy in DFIG wind power systems with current source converter" Conference of the IEEE Industrial Electronics Society, 29 Oct.-1 Nov. 2017. 
